\title{
Cephalopod species identification using integrated analysis of machine learning and deep learning approaches
}

\author{
Hui Yuan Tan ${ }^{1}$, Zhi Yun Goh ${ }^{1}$, Kar-Hoe Loh ${ }^{\text {Corresp., }}{ }^{2}$, Amy Yee-Hui Then ${ }^{3}$, Hasmahzaiti Omar ${ }^{3}$, Siow-Wee Chang ${ }^{\text {Corresp. }}$ \\ ${ }^{1}$ Bioinformatics Programme, Institute of Biological Sciences, Faculty of Science, Universiti Malaya, Kuala Lumpur, Malaysia \\ 2 Institute of Ocean \& Earth Sciences, Universiti Malaya, Kuala Lumpur, Malaysia \\ 3 Ecology Biodiversity Programme, Institute of Biological Sciences, Faculty of Science, Universiti Malaya, Kuala Lumpur, Malaysia \\ Corresponding Authors: Kar-Hoe Loh, Siow-Wee Chang \\ Email address: khloh@um.edu.my, siowwee@um.edu.my
}

Background Despite the high commercial fisheries value and ecological importance as prey item for higher marine predators, very limited taxonomic work has been done on cephalopods in Malaysia. Due to the soft-bodied nature of cephalopods, the identification of cephalopod species based on the beak hard parts can be more reliable and useful than conventional body morphology. Since the traditional method for species classification was time-consuming, this study aimed to develop an automated identification model that can identify cephalopod species based on beak images. Methods 174 samples of seven cephalopod species were collected from the west coast of Peninsular Malaysia. Both upper and lower beaks were extracted from the samples and the left lateral views of upper and lower beak images were acquired. Three types of traditional morphometric features were extracted namely grey histogram of oriented gradient (HOG), colour HOG, and morphological shape descriptor (MSD). In addition, deep features were extracted by using three pre-trained convolutional neural networks (CNN) models which areVGG19, InceptionV3, and Resnet50. Eight machine learning approaches were used in the classification step and compared for model performance. Results The results showed that the Artificial Neural Network (ANN) model achieved the best testing accuracy of $91.14 \%$, using the deep features extracted from the VGG19 model from lower beak images. The results indicated that the deep features were more accurate than the traditional features in highlighting morphometric differences from the beak images of cephalopod species. In addition, the use of lower beaks of cephalopod species provided better results compared to the upper beaks, suggesting that the lower beaks possess more significant morphological differences between the studied cephalopod species. Future works should include more cephalopod species and sample size to enhance the identification accuracy and comprehensiveness of the developed model. 
1 Cephalopod Species Identification Using Integrated Analysis of

2 Machine Learning and Deep Learning Approaches

4 Hui Yuan Tan ${ }^{1}$, Zhi Yun Goh ${ }^{1}$, Kar-Hoe Loh ${ }^{2 *}$, Amy Yee-Hui Then ${ }^{3}$, Hasmahzaiti Omar ${ }^{3}$, Siow-

5 Wee Chang ${ }^{1^{*}}$

$6{ }^{1}$ Bioinformatics Programme, Institute of Biological Sciences, Faculty of Science, Universiti

7 Malaya, Kuala Lumpur, Malaysia

$8{ }^{2}$ Institute of Ocean \& Earth Sciences, Universiti Malaya, Kuala Lumpur, Malaysia

$9{ }^{3}$ Ecology Biodiversity Programme, Institute of Biological Sciences, Faculty of Science,

10 Universiti Malaya, Kuala Lumpur, Malaysia

11

12

Corresponding authors:

Kar-Hoe Loh

Institute of Ocean \& Earth Sciences, Universiti Malaya, 50603 Kuala Lumpur, Malaysia

Email address: khloh@um.edu.my

Siow-Wee Chang

Bioinformatics Programme, Institute of Biological Sciences, Faculty of Science, Universiti Malaya, 50603, Kuala Lumpur, Malaysia

Email address: siowwee@um.edu.my 
30

31

32

\section{ABSTRACT}

\section{Background}

Despite the high commercial fisheries value and ecological importance as prey item for higher marine predators, very limited taxonomic work has been done on cephalopods in Malaysia. Due to the soft-bodied nature of cephalopods, the identification of cephalopod species based on the beak hard parts can be more reliable and useful than conventional body morphology. Since the traditional method for species classification was time-consuming, this study aimed to develop an automated identification model that can identify cephalopod species based on beak images.

\section{Methods}

174 samples of seven cephalopod species were collected from the west coast of Peninsular Malaysia. Both upper and lower beaks were extracted from the samples and the left lateral views of upper and lower beak images were acquired. Three types of traditional morphometric features were extracted namely grey histogram of oriented gradient (HOG), colour HOG, and morphological shape descriptor (MSD). In addition, deep features were extracted by using three pre-trained convolutional neural networks (CNN) models which areVGG19, InceptionV3, and Resnet50. Eight machine learning approaches were used in the classification step and compared for model performance.

\section{Results}

The results showed that the Artificial Neural Network (ANN) model achieved the best testing accuracy of $91.14 \%$, using the deep features extracted from the VGG19 model from lower beak images. The results indicated that the deep features were more accurate than the traditional features in highlighting morphometric differences from the beak images of cephalopod species. In addition, the use of lower beaks of cephalopod species provided better results compared to the upper beaks, suggesting that the lower beaks possess more significant morphological differences between the studied cephalopod species. Future works should include more cephalopod species and sample size to enhance the identification accuracy and comprehensiveness of the developed model. 
59

60

61

62

\section{Introduction}

Cephalopods (Phylum: Mollusca, Class: Cephalopoda) refer to a group of soft-bodied, bilaterally symmetrical animals with well-developed head and body, which includes octopus, squid, cuttlefish and nautilus. This taxon is the third largest molluscan class which comprises more than 800 described species in the world (Lindgren et al. 2004). Globally, cephalopods contribute as much as $55 \%$ of fishery landings and $70 \%$ in fishery value (USD) (Hunsicker et al., 2010). Their economic contribution as fisheries resources has been on the rise globally as the landings of finfish had decreased due to overfishing. Cephalopods also play an important role in marine food webs, particularly in supporting top marine predators such as sharks and dolphins (Wolff, 1984; Hunsicker et al., 2010).

In Malaysia, cephalopods contribute to about $12 \%$ of total fisheries landing valued at MYR1,067 million (approximately USD 250 million) in retail markets (Department of Fisheries Malaysia, 2015). The west coast of Peninsular Malaysia contributed more than $50 \%$ of the country's cephalopod landings, and the taxonomic composition was dominated by squids, followed by cuttlefish and octopus (Abu Talib and Mahyam, 1986). Limited local biodiversity surveys found 17 species from six families and common families included Sepiidae (cuttlefish), Octopodidae (octopus), and Loliginidae (squid) (Samsudin, 2001; Rubaie et al., 2012). Cephalopods are popular in local cuisines such as grilled squids (known locally as 'sotong bakar'), fried calamari, and dried squids. Despite their high fisheries profile and economic value as well as ecological importance, there has been virtually no comprehensive taxonomic studies on cephalopods in Malaysia.

One major reason for the lack of local taxonomic information on cephalopods is due to their soft body mass which renders morphological descriptions based on length measurements very challenging. The soft tissue nature makes these animals easily damaged during sampling and rapidly digested inside the stomachs of predators; only the intact upper and lower chitinized beaks will typically remain as evidence of their consumption (Markaida \& Hochberg, 2005). It had been established that the morphological characteristics of these beaks are species-specific and thus allow for taxonomic identification of the cephalopod prey from beaks isolated from stomach contents of their predators (Clarke 1962, 1986; Furness et al.,1984). The lower beak displays greater inter-specific morphological variations than the upper beak; thus the former is 
89

90

91

92

93

94

generally used for identification purpose (Xavier et al., 2011). The inclusion of beak size information has been shown useful to differentiate between two cephalopod species from the same family (Clarke, 1962).

Machine learning approaches such as Artificial Neural Network (ANN), k-Nearest Neighbors (kNN), Random Forest (RF), and Support Vector Machine (SVM) are used increasingly to automate taxonomic identification efforts and to improve accuracy of classification tasks. Many taxonomic studies to date focused on the application of machine learning in the identification of plant species (Tan et al. 2020; Murat et al. 2017), land animals (Nguyen et al., 2017; Norouzzadeh et al., 2018), and insects (Thenmozhi et al., 2020) while a small number of marine-related studies had been conducted with a focus on fish identification. Examples of these studies included the use of machine learning and deep learning methods for tracking and estimation of fish abundance (Marini et al., 2018), identification of fish species using whole-body images (Allken et al., 2018) and using otolith contours in fish species identification (Salimi et al., 2016).

Very limited machine learning techniques had been applied on cephalopod classification problems. Orenstain et al. (2016) used whole-body laboratory images of cuttlefish for classification of camouflaging behaviour with SVM classifiers. Beak and statolith images were used in the identification of three squid species found in the South China Sea (Jin et al., 2017). Himabindu et al. (2017) identified 50 squid species based on morphometric features measured from whole-body samples using ANN classifier. These examples showed the usefulness of machine learning methods for identification of cephalopods but their application had been limited to a single taxon (either cuttlefish or squid).

Hence, in this study, all three taxa of cephalopods namely squid, cuttlefish, and octopus were included. Images of whole body, upper beak and lower beak for all samples were taken. These images were then pre-processed using feature descriptors that extract useful information and omit extraneous ones. Specifically, traditional morphometric features were extracted from the images using three feature extraction methods, i.e., grey histogram of oriented gradient (HOG), colour HOG and morphological shape descriptors (MSD). For comparison, deep features were extracted using three convolutional neural networks (CNN) models namely VGG19, InceptionV3 and Resnet50. Next, a cephalopod species classification tool was developed using 
119 an integrated analysis of morphometric, machine learning and deep learning approaches. Eight 120 machine learning algorithms were analysed and benchmarked which included ANN, SVM, RF, 121 kNN, Decision Tree (DT), Logistic Regression (LR), Linear Discriminant Analysis (LDA), and 122 Gaussian Naïve Bayes (GNB). The proposed automated identification model will reduce time

123 needed for future cephalopod identification work and increase identification accuracy with 124 reduced costs. Our work also provides baseline estimate of species richness of cephalopods in 125 Peninsular Malaysia which is important for documentation of the country's rich marine 126 biodiversity.

\section{Materials \& Methods}

Generally, there were five main steps involved in this study namely sample collection, image acquisition, image processing, machine learning identification and model evaluation. Figure 1 shows the proposed framework of the cephalopod species identification model using an integrated analysis of machine learning and deep learning approaches. For sample collection, seven cephalopod species were acquired from fisheries landing sites and brought back to the laboratory for subsequent processing including beak extraction. For image acquisition, the images of both upper and lower beaks were captured by using a smartphone. In the image processing step, methods such as pre-processing, rescaling, and segmentation were performed on the images acquired, followed by feature extraction. In the machine learning identification step, eight machine learning methods were used to classify the cephalopod species. Finally, in the model evaluation step, both confusion matrix and precision-recall curve were used to evaluate the performance of the eight machine learning models.

\section{Sample Collection}

143 Sampling trips were conducted from November 2017 to January 2018. A total of 174 cephalopod 144 samples were collected from two major fisheries landing sites located on the west coast of 145 Peninsular Malaysia, namely Hutan Melintang, Perak and Pasir Penambang, Kuala Selangor. 146 The specimens were selected to represent the diversity of distinctive morphological groups and 147 size classes available during sampling. Seven putative cephalopod species were selected 
148 including four putative species for squid $(n=96)$, two for cuttlefish $(n=49)$ and one for octopus

$149(\mathrm{n}=29)$. Samples collected were kept on ice in the field and frozen immediately upon arrival in 150 the laboratory.

151

\section{Species Identification and Confirmation}

153 After defrosting, the specimens were measured for dorsal mantle length ( $\mathrm{mm})$ and wet body

154 mass (g) and were photographed (see steps described below). Initial species identification using 155 morphological characters were conducted using available taxonomic references (Reid et al., 1562005 , Jereb et al., 2016) and were cross-checked against current species checklists in reputable 157 databases, such as the Malaysia Biodiversity Information System (MyBIS, 2020), the World 158 Register of Marine Species (MolluscaBase eds., 2020), and SeaLifeBase (Palomares \& Pauly, 159 2020). The upper and lower beaks were then extracted from the buccal mass and preserved 160 separately in labelled jars containing $80 \%$ alcohol.

Species identification from morphological characteristics was subsequently confirmed with molecular approaches using the mitochondrial 16S rRNA gene which was amplified with the universal primers 16Sar and 16Sbr (Simon et al., 1994).

\section{Software and Hardware}

The hardware used for the image acquisition included a lightbox, a laptop (Intel i7 with 4 GB RAM), and a smartphone (16MP camera with 1440×250 pixels). The Adobe Photoshop CS6 (version 13.1.2) and Python 3 software were used in the feature extraction and identification step.

\section{Image Acquisition}

The images of both upper and lower beaks were captured using the Samsung Galaxy Note 4 smartphone camera. Samples were placed against a white background, i.e., lightbox with white light, and were centred on the camera screen to ensure high-quality images. A distance of $10 \mathrm{~cm}$ between the smartphone camera and the beak samples was fixed and no zooming was 
176

177

178

179

180

181

182

183

184

185

186

187

188

189

190

191

192

193

194

195

196

197

198

199

200

201

202

203

204

used for all specimens photographed (Figure 2). Only the left lateral views of the upper and lower beaks were captured. All beak images were stored using the JPEG format.

\section{Image Processing and Feature Extraction}

A digital image has to be processed before performing feature extraction and computational analysis to enhance the image, remove the noises, minimize the amount of storage needed and to increase the computation performance. Firstly, unwanted parts in the images were cropped. Next, all the beak images were downscaled to $10 \%$ of its original size to eliminate unnecessary pixel information without compromising the quality of the images. The original image resolution was $5312 \mathrm{px} \times 2988 \mathrm{px}$ while the rescaled image resolution was approximately $532 \mathrm{px} \times 299 \mathrm{px}$. Gaussian smoothing was then carried out on the rescaled images to reduce the noises on the images.

Image segmentation was performed to convert the rescaled images into red-green-blue (RGB) colour, grayscale and binary images to obtain the region of interest (ROI), which is the beak. Firstly, the colour space of the image was converted to the common RGB colour space. The colour image was then converted to a grayscale image by using equation (1) (OpenCV, 2020).

$$
Y=0.299(R)+0.587(G)+0.114(B)
$$

A thresholding algorithm was used to convert the grayscale image into a binary image by classifying all the pixels into two groups using a threshold value set at 240 . Those below the threshold value (0-239) formed the image background and those above the threshold (240-255) formed the object of interest, i.e. the beak. The boundary of the beak (ROI) was then determined, outlined and extracted from the image.

Next, HOG feature descriptor was calculated by determining the occurrences of gradients and orientation in localized portions of each image, i.e., an image is broken down into small regions and the gradients and orientation were calculated for each region. The magnitude of the gradient increases wherever there is a sharp change in intensity (brightness) of the image. The magnitude of the gradient, G was computed using equation (2) (Mallick, 2016). 
$205 \quad|G|=\sqrt{G_{x}^{2}+G_{y}^{2}}$

206 The gradient orientation, $\Theta$ was computed using equation (3) where $G_{x}$ is horizontal gradient in

207 the $X$ direction and $G_{y}$ is vertical gradient in the $Y$ direction (Mallick, 2016).

208

$$
\Theta=\arctan \frac{G_{x}}{G_{y}}
$$

209

210

211

212

213

214

215

216

217

218

219

220

221

222

223

224

225

226

227

228

229

230

231

232

A single image was divided into several cells, where each cell formed a square region which contained $128 \times 128$ pixels each. Using calculated gradient magnitude and orientation, every pixel within a cell casted a weighted vote for an orientation based histogram. The orientation bin was set as nine and this generated a frequency table for nine angles, i.e., 0, 20, 40, $60,80,100,120,140$ and 160 (Singh, 2019). Using the set number of bins, a $9 \times 1$ matrix histogram was counted for each cell. Next, $2 \times 2$ cells were grouped to form a block, resulting in a total of $3(3 \times 1)$ blocks of $128 \times 128$ pixels for each image. Each block contained four $9 \times 1$ or a single $36 \times 1$ matrix and a total of $108(3 \times 36 \times 1)$ features were produced for each image. In this manner, HOG was used in extracting the colour features from grayscale and RGB images and converted them into feature datasets.

The MSD consisted of both geometrical and morphological features (Aakif \& Khan, 2015) and extracted the shape features from the highlighted region in the binary images. The binary image is used commonly due to clear delineation of the boundary of the object. Firstly, the image was computed to determine the contour of the object. Then, all the noises were eliminated by adjusting the threshold. After the contour was shown, ten morphological features, including beak size, were extracted from each image (Table 1).

In addition to the traditional methods, three deep learning CNN models, namely VGG19, InceptionV3 and ResNet50, were used to automatically extract features from the images.. The VGG19 model consists of $3 \times 3$ convolutional layers. The original beak images were firstly resized to $224 \times 224$ pixels of RGB images as the inputs for VGG19. The VGG19 model preprocessed the images by subtracting the mean RGB value from each pixel of the image. Next, the max-pooling layer was used to reduce the feature dimensionality and two fully connected layers were used to produce the feature vector, with the presence of 4,096 neurons (Mateen et al., 2019). 
The InceptionV 3 model requires the input RGB image size of $299 \times 299$ pixels. Unlike the fixed kernel size for VGG19, the InceptionV3 allowed the features of the images to vary within an image frame and include multiple sizes of kernels in the same layer. There are four operations constructed in parallel, including a $1 \times 1$ convolutional layer for depth reduction, a $3 \times 3$ convolutional layer for capturing distributed features, a $5 \times 5$ convolutional layer for capturing the global features and a max-pooling layer for capturing the low-level features. Each layer is responsible to extract the deep features from the images, concatenate and pass them to the next layer (Anwar, 2019).

The ResNet50 model requires the input RGB image size of $224 \times 224$ pixels. ResNet50 is composed of 48 convolutional layers with $7 \times 7$ and $1 \times 1$ kernel size, max pooling layer and the fully connected layer. One of the important features of ResNet50 is the shortcut connections, that skip one or more layers, in order to solve the problem of vanishing gradient in deep neural networks by allowing the gradient to flow through the layer (Wen et al., 2019).

\section{Machine Learning Identification}

Machine learning techniques are capable of analysing weighty amounts of image data accurately and successfully. The supervised machine learning methods used for the cephalopod classification problem were Artificial Neural Network (ANN), Support Vector Machine (SVM), Random Forest (RF), Decision Tree (DT), k-Nearest Neighbours (kNN), Logistic Regression (LR), Linear Discriminant Analysis (LDA), and Gaussian Naïve Bayes (GNB). Table 2 shows the list of parameters adjusted for each classifier.

The ANN method is a machine learning technique that processes information by adopting the way neurons of human brains work and consists of a set of nodes that imitates the neuron and carries activation signals of different strengths (Daliakopoulos et al., 2005).

The SVM method is another popular algorithm in solving classification problems with limited amount of data. First, each sample data is plotted as a point in $n$-dimensional spaces, where $n$ is the number of features obtained from the image, also known as the support vectors. The SVM algorithm finds the best-fit hyperplane that maximizes the margin between the nearest support vectors of both classes with the hyperplane chosen (Yu \& Kim, 2012). 
262

263

264

265

266

267

268

269

270

271

272

273

274

275

276

277

278

279

280

281

282

283

284

285

286

287

288

289

290

A decision tree (DT) model is constructed for each feature selected. It starts from the root node and splits at the leaf nodes. Each leaf node determines the best split approach while the Gini impurity function is used to measure the quality of the split. The final leaf node shows the final prediction of each DT (Fan et al., 2006).

The RF method is a meta-estimator that fits several decision trees (DTs). The RF model is constructed and trained by the bagging method (decision tree) while the result is based on majority voting. All the predictions resulting from each DT are voted and the majority is the final output of the RF model (Svetnik et al., 2003).

For the kNN model, each data point is coordinated in the $n$-dimensional space while an unknown sample is introduced, the distance between the unknown sample with each data point is calculated based on the Euclidean distance matrix (Alimjan et al., 2018).

The multinomial LR model has two or more discrete outcomes where the most frequent species in the dataset was chosen as the reference category while the probability of other categories was compared against the reference category. This resulted in $n-1$ binary regression models, where $n=$ number of species in the classification problem. Prediction of the LR model is based on the Maximum Likelihood Estimation (MLE) approach, where the MLE determines the mean and variance that best describe the sample (Brownlee, 2019).

The LDA algorithm assumes that each feature has the same variance and calculates the between-class and within-class variance (Balakrishnama \& Ganapathiraju, 1998). The LDA approach maximizes the between-class variance and minimizes the within-class variance. Once the LDA model is trained, the probability of an unknown sample is calculated by using the Bayes Theorem (Hamsici \& Martinez, 2008). The result of the prediction is chosen based on the highest probability of the species.

The normal distribution method is also applied in the GNB model that estimates the mean and standard deviation of each species from the training data given. The Bayes Theorem is applied to calculate the probabilities of each species. Species with the highest probability matched will be selected (Pattekari \& Parveen, 2012).

The features extracted from each feature extraction methods were used as the input datasets in the machine learning identification step. Each dataset was split into $80 \%$ of training 
291 and $20 \%$ of the testing set. The training set was used to trained all eight models by minimizing

292 the error formed while the model performance was evaluated using the testing dataset. Five-fold 293 cross-validation (CV) stratified shuffle split method was used and tested for 10 times to avoid 294 any overfitting. A significant feature of stratified shuffle split is the ability to preserve the ratio 295 of the training and testing set in the dataset. Figure 3 shows an example of sample splitting for 296 one of the ANN models.

297

298

299

300

301

302

303

304

305

306

307

308

309

310

311

312

313

314

315

316

317

\section{Performance Evaluation}

The performance of the classification model was evaluated through the confusion matrix, i.e., a table that displays the number of true positives (TP), true negatives (TN), false positives (FP) and false negatives (FN). The testing accuracy, precision and recall were calculated using equations (7) to (9) respectively.

$$
\begin{aligned}
& \text { Testing accuracy }=\frac{\mathrm{TP}+\mathrm{TN}}{\mathrm{TP}+\mathrm{TN}+\mathrm{FP}+\mathrm{FN}} \\
& \text { Precision }=\frac{T P}{T P+F P} \\
& \text { Recall }=\frac{T P}{T P+F N}
\end{aligned}
$$

In addition, the performance of each classifier model was visualized from the area under the Precision-Recall (PR) curve (AUC), where the precision value was plotted on the $y$-axis while the recall value at the $\mathrm{x}$-axis (Narkhede, 2018). The precision and recall values were computed from the testing set for each cephalopod species and the average AUC of each model was calculated. The higher the AUC, the better the model performance in identifying cephalopod species from the beak images. According to Saito \& Rehmsmeier (2015), the PR curve is more informative and reliable than the Receiver Operating Characteristic (ROC) curve for imbalanced datasets.

\section{Results}

\section{Data Collection and Feature Extraction}


318

319

320

321

322

323

324

325

326

327

328

329

330

331

332

333

334

335

336

337

338

339

340

341

342

343

344

345

346

Seven species of cephalopod were morphologically identified (Table 3) and confirmed through 16S rRNA sequencing (Table 4). Out of these, two species were cuttlefish (Sepia aculeata, and Sepia esculenta), four were squids (Sepioteuthis lessoniana, Loliolus uyii, Uroteuthis chinensis and Uroteuthis edulis) and one was an octopus (Amphioctopus aegina).

A range of 10 to 108 features such as shape and colour features were extracted from the left lateral beak images using HOG and MSD descriptors. Using deep learning methods of VGG19, ResNet50 and InceptionV3, 2048 to 4096 features were extracted. Table 5 lists the number of traditional and deep features extracted by each descriptor.

\section{Traditional Features}

Firstly, the extracted features were tested individually as a single descriptor of grey HOG, colour HOG and MSD. Each of the descriptors was fit into eight different classifiers to test for the model performance in identifying the cephalopod species. Five-fold cross-validation with $80 \%-20 \%$ stratified shuffle splitting was used to avoid overfitting. Each test was continuously run for 10 times to achieve more reliable results. The testing results were averaged and the PR curves were plotted based on the descriptors used. Table 6 shows the average testing accuracy of each classifier with traditional descriptors for the upper and lower beak images. Grey HOG descriptors achieved the highest testing accuracy of $55.43 \%( \pm 0.14)$ for the KNN model using upper beak images while HOG descriptors with ANN achieved the best accuracy of $68.69 \%$ ( \pm 0.12 ) with lower beak images. MSD descriptors with GNB achieved the best accuracy at $64.00 \%$ $( \pm 0.11)$ using the upper beak images.

Next, the descriptors were combined as the hybrid descriptors which are (grey HOG + MSD) and (colour HOG + MSD) and tested. Table 6 shows the average testing accuracy of each classifier with hybrid descriptors. The hybrid descriptors of (Grey HOG + MSD) and (colour HOG + MSD) with ANN had the best testing accuracy at $61.09 \%( \pm 0.14)$ for the upper beak image and 73.09\% ( \pm 0.12$)$ for lower beak images. An improvement in the testing accuracy was observed in comparison with the single descriptor with the increment from $68.69 \%$ to $73.09 \%$ for the ANN model with lower beak images. Figure 4(a) shows the confusion matrix from one of the runs of the ANN model for hybrid descriptor (colour HOG + MSD) and lower beak image. 
347 The ANN model appeared to classify the test samples of S. esculenta and L. uyii perfectly. The

348 performance of the ANN model can be observed through the precision recall-curve (Figure 349 4(b)).

350

351

\section{Deep Features}

352

353

354

355

356

357

358

359

360

361

362

363

364

365

366

367

368

369

370

371

372

373

374

375

Both upper and lower beak images were used as inputs into CNN models to extract the deep features. Table 7 shows the average testing accuracy of each classifier with deep features extracted. All CNN models achieved good results with the best result of $91.14 \%( \pm 0.09)$, $89.43 \%$ ( \pm 0.09$)$, and 86.86\% ( \pm 0.09$)$ for VGG19, InceptionV3 and ResNet50 respectively. Figure 5(a) shows the confusion matrix from one of the runs of the ANN model for deep features extracted from the VGG19 with lower beak images. The ANN model was shown to classify most of the species perfectly, except for S. esculenta and L. uyii. The performance of the ANN model can be observed through the precision recall-curve (Figure 5(b)).

\section{Discussion}

To the best of our knowledge, this automated identification study is the first of its kind using beak images from cephalopods sampled in the region of Southeast Asia. In general, the easiest way to identify a cephalopod species is based on the appearance of the whole-body. This approach however hinges on one having access to a readily available, comprehensive taxonomic key and working with fresh or well-preserved whole specimens. Development of an identification approach using cephalopod hard parts, especially beaks, is fundamentally important to resolve species identity from digested cephalopod within stomachs of predators. Our study takes this approach further to develop an automated classification of beak images, thus widening the toolkit available for species identification with lesser reliance on manual labour.

It should be clarified that the method developed in this study could also be applied to images of whole cephalopod bodies. However, their soft-bodied nature makes them difficult to manipulate, easily broken during sampling, cleaning and photographing processes, as well as rapidly decay. Based on the samples collected in our study, the tiny, long tentacles of the cephalopod were mostly broken prior to the image acquisition process. This may cause some 
376 errors in extracting useful information from whole body images, such as shape features of the

377 cephalopods. Therefore, images of beaks instead of whole bodies were chosen to train each

378 classifier to obtain an automated cephalopod species identification model.

379 We used a smartphone to capture the beak images as this is a readily available tool that can be used by both researchers and citizen scientists. The smartphone was relatively easy to

381

382

383

384

385

386

387

388

389

390

391

392

393

394

395

396

397

398

399

400

401

402

403

404

405

handle and could be focused on the small-sized beak and adjusted for specific angles. During the image acquisition, the left lateral view of the upper beak and lower beak was taken and used in training the cephalopod species identification model. The left lateral view of the beaks was found to provide more distinctive features among the seven cephalopod species collected. The lowquality images did render the image pre-processing more challenging, specifically the actual edge of the beak and the background could not be differentiated. Some noises were left and may affect the quality of information extracted. Nevertheless, the image segmentation process through the thresholding method had efficiently eliminated the noises left in the images and increased the accuracy of the features extracted from the beak images.

From the results shown in Table 6, the colour feature was found to be better than shape features in differentiating the beaks extracted from each cephalopod species. The HOG descriptor had obtained the best accuracy of $68.69 \%$ using ANN and lower beak images. The main reason for this is due to the limited shape features extracted from the beak images which led to difficulty in resolving the tiny differences between the beaks of each cephalopod species. Also, the colour HOG gave better results than the grey HOG descriptor in extracting the colour features from the cephalopod beak images. The gradient or colour changes of the species-specific beaks were significantly distinguished by the three colour channel images (RBG) of the colour HOG descriptor instead of the single colour channel (grey-level intensity) of the grey HOG descriptor. The better performance of the beak colour feature for species identification can also be explained by the close relationship between the beak's darkening stages and age for each cephalopod family (Clarke, 1962).

The model performance of the selected classifier increased by combining two out of the three single descriptors. The hybrid descriptor of (colour HOG + MSD) obtained the highest accuracy of $73.09 \%$ with the ANN model and lower beak images. The combination of the colour and the shape features had provided more details in differentiating the seven cephalopod species

Peer] reviewing PDF | (2020:10:54676:3:0:NEW 21 Jun 2021) 
406 from the beak image provided. The hybrid features can best describe the differences between the

407 beaks since the colour information or the shape information can support each other and result in

408 a higher accuracy of the identification model. The ANN model worked better with hybrid

409 descriptors as the ANN classifier usually performed the best in classification problems which

410 involve small sample sizes (Pasini, 2015).

411 Incorporation of the deep features (Table 7) greatly improved the accuracy of the

412 identification model. The pre-trained CNN model helped to scan the beak images, searched for

413 features that were correlated to the classification problem and combined all the selected features

414 as the input feature vector. Most of the classifiers could achieve accuracy of more than $85 \%$ with

415 the deep features, except for DT. The lower accuracy of the DT model was due to the insufficient

416 samples provided. DT model tended to overfit as compared to other classifiers and resulted in

417 lower accuracy (Liu et al., 2005). This was because the DT model used only one tree to make the

418 node splitting and generalization. However, by increasing the number of trees, such as in RF, it

419 could overcome the weakness of DT. Since the sample size of this study was small for each

420 cephalopod species, only the important features that can best describe the differences between

421 the cephalopod species were required to train the classifiers. Too many features in the input may

422 cause overfitting, i.e. a well fitted model with data provided but with weak power of

423 generalisation and low accuracy of prediction (Loughrey \& Cunningham, 2004). For example,

424 the RF and LDA models showed overfitting, as testing accuracy was much lower than the

425 training accuracy. This overfitting problem could be minimized with larger sample sizes for

426 future studies (Steyerberg, 2019).

427 The performance of this study was compared to some related previous studies as shown in

428 Table 8. These studies either involved only one type of cephalopod species (Orenstein et al.,

429 2016), or using the whole-body morphometric measurements of squids (Himabindu et al., 2017)

430 and there were no deep features extracted (Jin et al., 2017; Himabindu et al., 2017; Orenstein et

431 al., 2016). The most distinct advantage of this study is the introduction of the deep features in

432 identifying the cephalopod species using upper and lower beaks. From the results of this study,

433 the deep features are better suited in describing the characteristics of cephalopod beaks of each

434 species than the traditional features. 
435

436

437

438

439

440

441

442

443

444

445

446

447

448

449

450

451

452

453

454

455

456

457

458

459

460

461

462

463

464

Our study comparing lower and upper beak images is in concordance with findings from other studies that lower beaks are more useful in species identification for cephalopods (Richoux et al., 2010; Xavier et al. 2011). However, for applications of the model to quantify cephalopod prey contributions, improving species identification from upper beaks remain an area of priority due to differing numbers of lower and upper beak samples in studies of the same predator stomachs (Xavier et al. 2011). Future work in evaluating the performance of the beak images for identification of cephalopods from stomach contents should also focus on evaluating accuracy of identification on both fresh and old samples of beaks due to varying degree of erosion of the beak materials (Xavier et al., 2015).

Our limited sampling from the two locations within the Strait of Malacca over a short time duration originally yielded 18 putative species of cephalopods; however only five cuttlefishes, five squids, and three octopus could be identified to the species level out of seven cuttlefishes, six squids, and five octopus putative species respectively (Muhammad, 2017). Seven of these cephalopod species had sufficient sample sizes which allowed their inclusion in this machine learning study. The best estimated species richness of cephalopods for the Strait area is 33 species from a global study that focused only on coastal cephalopods (Rosa et al., 2019). For context, the Strait is one of the three hotspot ecoregions for cephalopod species richness within the Indo-Pacific area, and inshore squids made up 11 out of the 33 species, and this species richness is likely an underestimation (Rosa et al., 2019). Thus the number of species included in the automated identification model developed in this work represented about $20 \%$ of the best species richness estimate. In general, classification error would reduce with increasing sample size per class, or species in this case (Jain et al., 2000). Therefore, future research work should focus on increasing images per species and including the unsampled species within the model development and validation.

\section{Conclusions}

Traditional features and deep features were extracted from beak images of seven cephalopod species and evaluated using eight classifiers. This study found that ANN achieved the best testing accuracy of $91.14 \%$ with deep features extracted by the VGG19 from the lower beak images. Deep features performed better than the traditional features and lesser pre- 
465

466

467

468

469

470

471

472

473

474

475

476

477

478

479

480

481

482

483

484

485

486

487

488

489

490

491

492

493

494

495

496

processing works are needed for deep feature extraction. However, there are some limitations in this proposed model which included unbalanced and limited sample size, a single view of beak included and the limited number of shape features in the MSD descriptors. Hence, future works should include increasing the species variety and the number of samples, adding more shape features such as convex area, eccentricity, and Euler number, and also evaluation of other CNN models. These approaches may help to recognize the minor beak differences between the cephalopod species by increasing details in the extracted features.

\section{Acknowledgements}

Sincerely thanks to Mr. Muhammad Azwan Bin Yahaya from Programme Biodiversity and Ecology, postgraduate students from the Institute of Advanced Studies, UM and staff from IOES for their help provided during the sample collection.

\section{References}

Aakif, A., \& Faisal Khan, M. (2015). Automatic classification of plants based on their leaves (Vol. 139).

Abu Talib, and Isa, M., 1986. The squid and cuttlefish resources in Peninsular Malaysia. Fisheries Bulletin 45, Department of Fisheries Malaysia. 32 p.

Alimjan, G., Sun, T., Liang, Y., Jumahun, H., \& Guan, Y. (2018). A new technique for remote sensing image classification based on combinatorial algorithm of SVM and KNN. International Journal of Pattern Recognition and Artificial Intelligence, 32(07), 1859012.

Allken, V., Handegard, N. O., Rosen, S., Schreyeck, T., Mahiout, T., \& Malde, K. (2018). Fish species identification using a convolutional neural network trained on synthetic data. ICES Journal of Marine Science, 76(1), 342-349.

Anwar, A. (2019, Jun 7). Difference between AlexNet, VGGNet, Resnet and Inception. Towards Data Science. Retrieved on 20 September 2020 from https://towardsdatascience.com/thew3h-of-alexnet-vggnet-resnet-and-inception-7baaaeccc96

Balakrishnama, S., \& Ganapathiraju, A. (1998, March). Linear discriminant analysis-a brief tutorial. In Institute for Signal and information Processing (Vol. 18, No. 1998, pp. 1-8).

Brownlee, J. (2019, October 28). A Gentle Introduction to Logistic Regression With Maximum Likelihood Estimation. Machine Learning Mastery. Retrieved on 20 September 2020 
497

498

499

500

501

502

503

504

505

506

507

508

509

510

511

512

513

514

515

516

517

518

519

520

521

522

523

524

525

526

527

528

529

530

531

532

533

from https://machinelearningmastery.com/logistic-regression-with-maximum-likelihoodestimation/

Clarke, M.R. (1962). Significance of cephalopod beaks. Nature. 193(4815). 560-561. Retrieved on 25 January 2021 from https://doi.org/10.1038/193560a0.Clarke M. R. (1986). Handbook for the identification of cephalopods beaks. Clarendon Press, Oxford.

Daliakopoulos, I., Coulibaly, P., \& K. Tsanis, I. (2005). Groundwater Level Forecasting Using Artificial Neural Network (Vol. 309).

Department of Fisheries Malaysia. (2015). Annual Fisheries Statistics 2015. Retrieved October 20, 2020, from https://www.dof.gov.my/index.php/pages/view/3073.

Fan, G. Z., Ong, S. E., \& Koh, H. C. (2006). Determinants of house price: A decision tree approach. Urban Studies, 43(12), 2301-2315.

Fries, A.S. (2010). A Gap Analysis Of The Distributions Of Cephalopod Species Worldwide.

Furness, B. L., Laugksch, R. C., \& Duffy, D. C. (1984). Cephalopod beaks and studies of seabird diets. The Auk, 101(3), 619-620.

Hamsici, O. C., \& Martinez, A. M. (2008). Bayes optimality in linear discriminant analysis. IEEE transactions on pattern analysis and machine intelligence, 30(4), 647657.

Himabindu, K., Jyothi, S., \& Mamatha, D. (2017). Classification of Squids Using Morphometric Measurements. Gazi University Journal of Science, 30(2), 61-71. Retrieved on 16 September 2019 from http://gujs.gazi.edu.tr/article/view/ 5000209462/5000182050

Hunsicker, M.E., Essington, T.E., Watson, R. and Sumaila, U.R., 2010. The contribution of cephalopods to global marine fisheries: can we have our squid and eat them too? Fish and Fisheries, 11(4), pp.421-438.

Jain, A. K., Duin, R. P. W., \& Mao, J. (2000). Statistical pattern recognition: A review. IEEE Transactions on pattern analysis and machine intelligence, 22(1), 4-37.

Jereb, P., Roper, C.F.E., Norman, M.D., \& Finn, J.K. (2016). Cephalopods of the world. An annotated and illustrated catalogue of cephalopod species known to date. vol 3. Octopods and vampire squids. FAO Species Catalogue for fishery purposes 4, FAO, Rome, pp 352.

Jin, Y., Liu, B., Li, J., \& Chen, X. (2017). Identification of three common Loliginidae squid species in the South China Sea by analyzing hard tissues with geometric outline method. Journal of Ocean University of China, 16(5), 840-846.

Lindgren, A. R., Giribet, G., \& Nishiguchi, M. K. (2004). A combined approach to the phylogeny of Cephalopoda (Mollusca). Cladistics, 20(5), 454-486.

Liu, B. L., \& Chen, X. J. (2009). Review on the research development of beaks in Cephalopoda. Journal of Fisheries of China, 33(1), 157-164.

Liu, Y. H., Niu, Z., \& Wang, C. Y. (2005). Study and application of the decision tree classification using MODIS data. Journal of Remote Sensing Beijing, 9(4), 405. 
534

535

536

537

538

539

540

541

542

543

544

545

546

547

548

549

550

551

552

553

554

555

556

557

558

559

560

561

562

563

564

565

566

567

568

569

570

571

Loughrey, J., \& Cunningham, P. (2004, December). Overfitting in wrapper-based feature subset selection: The harder you try the worse it gets. In International Conference on Innovative Techniques and Applications of Artificial Intelligence (pp. 33-43). Springer, London.

Malaysia Biodiversity Information System (MyBIS). (2020). https://www.mybis.gov.my/ Downloaded on 14 October 2020

Mallick, S. (2016, December 06). Histogram of Oriented Gradients. Retrieved May 19, 2018, from https://www.learnopencv.com/histogram-of-oriented-gradients/

Marini, S., Fanelli, E., Sbragaglia, V., Azzurro, E., Fernandez, J. D. R., \& Aguzzi, J. (2018). Tracking fish abundance by underwater image recognition. Scientific Reports, 8(1), 1-12.

Markaida, U., \& Hochberg, F. G. (2005). Cephalopods in the diet of swordfish (Xiphias gladius) caught off the west coast of Baja California, Mexico. Pacific Science, 59 (1), 25-41.

Mateen, M., Wen, J., Song, S., \& Huang, Z. (2019). Fundus image classification using VGG-19 architecture with PCA and SVD. Symmetry, 11(1), 1.

Medjahed, S. A. (2015). A comparative study of feature extraction methods in images classification. International journal of image, graphics and signal processing, 7(3), 16.

MolluscaBase eds. (2020). MolluscaBase. Sepiidae Leach, 1817. Accessed through: World Register of Marine Species at: https://www.marinespecies.org/aphia.php?p= taxdetails\&id=11723 on 2020-10-14

Muhammad, A. Y. (2017). Morphological study of cephalopods in the central west coast of Peninsular Malaysia (Unpublished undergraduate thesis). Universiti Malaya, Kuala Lumpur, Malaysia.

Murat, M., Chang, S.W., Abu, A., Yap, H.J., Yong, K.T. (2017) Automated classification of tropical shrub species: a hybrid of leaf shape and machine learning approach. PeerJ, 5, e3792.

Narkhede, S. (2018, May 9). Understanding Confusion Matrix. Retrieved on 28 May 2020 from https://towardsdatascience.com/understanding-confusion-matrix-a9ad42dcfd62

Nguyen, H., Maclagan, S. J., Nguyen, T. D., Nguyen, T., Flemons, P., Andrews, K., \& Phung, D. (2017, October). Animal recognition and identification with deep convolutional neural networks for automated wildlife monitoring. In 2017 IEEE international conference on data science and advanced Analytics (DSAA) (pp. 40-49). IEEE.

Norouzzadeh, M. S., Nguyen, A., Kosmala, M., Swanson, A., Palmer, M. S., Packer, C., \& Clune, J. (2018). Automatically identifying, counting, and describing wild animals in camera-trap images with deep learning. Proceedings of the National Academy of Sciences, 115(25), E5716-E5725.

OpenCV. (2020, Oct 29). Color Conversions. Retrieved on 29 October 2020 from https://docs.opencv.org/3.4/de/d25/imgproc_color_conversions.html

Orenstain, E.C., Haag, J.M., Gagnon, Y.L., \& Jaffe, J.S. (2016). Automated classification of camouflaging cuttlefish. Methods in Oceanography, 15-16, 21-34. Retrieved on 16 
572

573

574

575

576

577

578

579

580

581

582

583

584

585

586

587

588

589

590

591

592

593

594

595

596

597

598

599

600

601

602

603

604

605

606

607

608

609

610

611

September 2019 from https://www.sciencedirect.com/

science/article/pii/S2211122015300220.

Palomares, M.L.D., \& D. Pauly. Editors. (2020). SeaLifeBase. World Wide Web electronic publication. www.sealifebase.org, version (07/2020).

Pasini, A. (2015). Artificial neural networks for small dataset analysis. Journal of thoracic disease, 7(5), 953.

Pattekari, S. A., \& Parveen, A. (2012). Prediction system for heart disease using Naïve Bayes. International Journal of Advanced Computer and Mathematical Sciences, 3(3), 290-294.

Reid, A., Jereb, P. \& Roper, C.F.E. (2005). Family Sepiidae. pp. 57-152, in P. Jereb \& C.F.E. Roper eds. Cephalopods of the world. An annotated and illustrated catalogue of cephalopod species known to date. Volume 1. Chambered nautiluses and sepioids (Nautilidae, Sepiidae, Sepiolidae, Sepiadariidae, Idiosepiidae and Spirulidae). FAO Species Catalogue for Fishery Purposes [Rome, FAO]. 4(1): 262 pp. 9 pls.

Richoux, N. B., Jaquemet, S., Bonnevie, B. T., Cherel, Y., and McQuaid, C. D. (2010). Trophic ecology of grey-headed albatrosses from Marion Island, Southern Ocean: insights from stomach contents and diet tracers. Marine Biology, 157, 1755-1766.

Rosa, R., Pissarra, V., Borges, F. O., Xavier, J., Gleadall, I. G., Golikov, A., ... \& Villanueva, R. (2019). Global patterns of species richness in coastal cephalopods. Frontiers in Marine Science, 6, 469.

Rubaie, Z.M., Idris, M.H., Kamal, A.H.M. and King, W.S., 2012. Diversity of cephalopod from selected division of Sarawak, Malaysia. International Journal on Advanced Science, Engineering and Information Technology, 2(4), pp.279-281.

Saito, T., \& Rehmsmeier, M. (2015). The precision-recall plot is more informative than the ROC plot when evaluating binary classifiers on imbalanced datasets. PloS one, 10(3), $\mathrm{e} 0118432$.

Salimi, N., Loh, K. H., Dhillon, S. K., \& Chong, V. C. (2016). Fully-automated identification of fish species based on otolith contour: using short-time Fourier transform and discriminant analysis (STFT-DA). PeerJ, 4, e1664.

Samsudin, B. (2001). Distribution and population biology of Cephalopods in the EEZ of Malaysia: Analysis from the survey data in 1997/78 In: Mohd-Taupek, M. N., \& Mansor, M. I. (eds.). Fisheries resources survey in the Exclusive Economic Zone of Malaysia 1997-1999: Biology and Environmental Conditions (Supplementary Volume), Department of Fisheries, Ministry of Agriculture Malaysia.

Simon, C., Frati, F., Beckenbach, A., Crespi, B., Liu, H., Flook, P. (1994). Evolution, weighting, and phylogenetic utility of mitochondrial gene sequences and a compilation of conserved polymerase chain reaction primers. Ann. Entomol. Soc. Am. 87, 652-701.

Singh, A. (2019, September 4). Feature Engineering for Images: A Valuable Introduction to the HOG Feature Descriptor. Retrieved on 25 April 2020 from 
612

613

614 615

616

617

618

619

620

621

622

623

624

625

626

627

628

629

630

631

632

633

634

635

636

637

https://www.analyticsvidhya.com/blog/2019/09/feature-engineering-images-introductionhog-feature-descriptor/

Steyerberg, E. W. (2019). Overfitting and optimism in prediction models. In Clinical Prediction Models (pp. 95-112). Springer, Cham.

Svetnik, V., Liaw, A., Tong, C., Culberson, J. C., Sheridan, R. P., \& Feuston, B. P. (2003). Random forest: a classification and regression tool for compound classification and QSAR modeling. Journal of chemical information and computer sciences, 43(6), 19471958.

Tan, J.W., Chang, S.W., Abdul-Kareem, S., Yap, H.J., Yong, K.T. (2020). Deep Learning for Plant Species Classification using Leaf Vein Morphometric, IEEE-ACM Transactions on Computational Biology and Bioinformatics, 17 (1), pp 82-90.

Thenmozhi K., Dakshayani S., Srinivasulu R. U. (2020) Insect classification and detection in field crops using modern machine learning techniques. Information Processing in Agriculture. In press. https://doi.org/10.1016/j.inpa.2020.09.006

Vendetti, J. (2006). The Cephalopoda. UCMP. Retrieved on 21 April 2020 from https://ucmp.berkeley.edu/taxa/inverts/mollusca/cephalopoda.php

Wen, L., Li, X., \& Gao, L. (2019). A transfer convolutional neural network for fault diagnosis based on ResNet-50. Neural Computing and Applications, 1-14.

Wolff, G.A., 1984. Identification and estimation of size from the beaks of 18 species of cephalopods from the Pacific Ocean. NOAA Technical Report NMFS 17, $50 \mathrm{p}$.

Xavier, J. C., Phillips, R. A., \& Cherel, Y. (2011). Cephalopods in marine predator diet assessments: why identifying upper and lower beaks is important. ICES Journal of Marine Science, 68(9), 1857-1864.

Xavier, J. C., Allcock, A. L., Cherel, Y., Lipinski, M. R., Pierce, G. J., Rodhouse, P. G., ... \& Ziegler, A. (2015). Future challenges in cephalopod research. Journal of the Marine Biological Association of the United Kingdom. 95(5), 999-1015. 
Table $\mathbf{1}$ (on next page)

List of morphological features 
Table 1: List of morphological features

\begin{tabular}{|c|c|c|}
\hline Features & Definition & Formula \\
\hline Area & Size of the beak & - \\
\hline Perimeter & The length of the contour of the beak & - \\
\hline \multirow{2}{*}{ Aspect Ratio } & \multirow{2}{*}{$\begin{array}{l}\text { The ratio of major axis length over } \\
\text { minor axis length }\end{array}$} & width $(w)$ \\
\hline & & $\overline{\text { height }(h)}$ \\
\hline \multirow{2}{*}{ Extent } & \multirow{2}{*}{$\begin{array}{l}\text { The proportion of pixels in the } \\
\text { bounding box that also contains the } \\
\text { beak. }\end{array}$} & area \\
\hline & & $\overline{\text { bounding box area }}$ \\
\hline \multirow{2}{*}{$\begin{array}{l}\text { Solidity / } \\
\text { convexity }\end{array}$} & \multirow{2}{*}{$\begin{array}{l}\text { The proportion of the pixels in the } \\
\text { convex hull that also contains beak. }\end{array}$} & area \\
\hline & & $\overline{c o n v e x ~ h u l l ~ a r e a}$ \\
\hline \multirow{2}{*}{$\begin{array}{l}\text { Equivalent } \\
\text { Diameter }\end{array}$} & \multirow{2}{*}{$\begin{array}{l}\text { The diameter of a circle with the same } \\
\text { area as the beak }\end{array}$} & $(4 \times$ area $)$ \\
\hline & & pi \\
\hline \multirow{2}{*}{ Circularity } & \multirow{2}{*}{$\begin{array}{l}\text { The ratio of the area of the beak to the } \\
\text { convex circle }\end{array}$} & $(4 \times$ pi $x$ area $)$ \\
\hline & & $\left(_{(\text {convex perimeter })^{2}}\right.$ \\
\hline \multirow{2}{*}{ Rectangularity } & \multirow{2}{*}{$\begin{array}{l}\text { The ratio of the beak to the area of the } \\
\text { minimum bounding rectangle }\end{array}$} & $w \times h$ \\
\hline & & $\overline{\text { bounding box area }}$ \\
\hline \multirow{2}{*}{ Form Factor } & \multirow{2}{*}{$\begin{array}{l}\text { The ratio of the area of the beak to the } \\
\text { circle }\end{array}$} & $(4 \times$ pi $x$ area $)$ \\
\hline & & perimeter $^{2}$ \\
\hline \multirow{2}{*}{ Narrow Factor } & \multirow{2}{*}{$\begin{array}{l}\text { The ratio of the diameter of the beak to } \\
\text { the height of the beak }\end{array}$} & equivalent diameter \\
\hline & & $h$ \\
\hline
\end{tabular}

2 
Table 2 (on next page)

List of parameters adjusted for each classifier 
$1 \quad$ Table 2: List of parameters adjusted for each classifier

\begin{tabular}{|l|l|}
\hline Classifiers & Parameters \\
\hline ANN & $\begin{array}{l}\text { Hidden layer sizes }=1 \text { layer and 30 hidden neurons, Learning rate } \\
\text { schedule for weight updates }=0.001 \text {, Maximum number of iteration }= \\
\text { 200, Weight optimization }=\text { stochastic gradient-based optimizer }\end{array}$ \\
\hline SVM & $\begin{array}{l}\mathrm{C}=30, \text { Decision function shape }=\text { One-vs-one decision function, Kernel } \\
\text { type }=\text { 'sigmoid' }\end{array}$ \\
\hline RF & $\begin{array}{l}\text { Number of trees }=100, \text { Function in measuring the quality of split = 'Gini } \\
\text { impurity', Maximum number of features = sqrt(number of features) }\end{array}$ \\
\hline DT & $\begin{array}{l}\text { Function in measuring the quality of split = Information gain, Maximum } \\
\text { depth of the tree }=2\end{array}$ \\
\hline KNN & $\begin{array}{l}\text { Distance metric }=\text { minkowski (standard Euclidean metric), Number of } \\
\text { neighbors }=8, \text { Weights function }=\text { uniform weights }\end{array}$ \\
\hline LR & $\begin{array}{l}\text { C }=0.15, \text { Multiclass }=\text { multinomial loss fit across the probability } \\
\text { distribution, Weight optimization algorithm = newton-cg }\end{array}$ \\
\hline LDA & $\begin{array}{l}\text { C }=0.15, \text { Weight optimization }=\text { Singular value decomposition, tol = } \\
0.0001\end{array}$ \\
\hline GNB & Largest variance for calculation stability = 1e-09 \\
\hline
\end{tabular}

2 Notes:

$\mathrm{C}=$ regularization parameter based on the squared 12 penalty, the smaller the strong regularization power, tol $=$ tolerance for stopping criteria 
Table 3 (on next page)

List of the Cephalopod Species Collected 
1 Table 3: List of the Cephalopod Species Collected

\begin{tabular}{|c|c|c|c|}
\hline $\begin{array}{l}\text { Scientific Name } \\
\text { (Common Name) }\end{array}$ & $\begin{array}{l}\text { Upper Beak } \\
\text { Image* }\end{array}$ & $\begin{array}{l}\text { Lower beak } \\
\text { Image* }\end{array}$ & $\begin{array}{l}\text { Sample } \\
\text { size }\end{array}$ \\
\hline $\begin{array}{l}\text { Sepia aculeata } \\
\text { (Needle cuttlefish) }\end{array}$ & $\mathrm{Size} \approx 1 \mathrm{~cm}$ & $\mathrm{Size} \approx 1 \mathrm{~cm}$ & 25 \\
\hline $\begin{array}{l}\text { Sepia esculenta } \\
\text { (Golden cuttlefish) }\end{array}$ & Size $\approx 1 \mathrm{~cm}$ & $\mathrm{Size} \approx 1 \mathrm{~cm}$ & 24 \\
\hline $\begin{array}{l}\text { Amphioctopus aegina } \\
\text { (Sandbird octopus) }\end{array}$ & Size $\approx 0.5 \mathrm{~cm}$ & $\mathrm{Size} \approx 0.5 \mathrm{~cm}$ & 29 \\
\hline $\begin{array}{l}\text { Sepioteuthis lessoniana } \\
\text { (Bigfin reef squid) }\end{array}$ & $\mathrm{Size} \approx 1 \mathrm{~cm}$ & $\mathrm{Size} \approx 1 \mathrm{~cm}$ & 17 \\
\hline $\begin{array}{l}\text { Loliolus uyii } \\
\text { (Little squid) }\end{array}$ & Size $\approx 0.5 \mathrm{~cm}$ & Size $\approx 0.5 \mathrm{~cm}$ & 32 \\
\hline $\begin{array}{l}\text { Uroteuthis chinensis } \\
\text { (Mitre squid) }\end{array}$ & Size $\approx 0.5 \mathrm{~cm}$ & Size $\approx 0.5 \mathrm{~cm}$ & 19 \\
\hline $\begin{array}{l}\text { Uroteuthis edulis } \\
\text { (Swordtip squid) }\end{array}$ & Size $\approx 0.5 \mathrm{~cm}$ & Size $\approx 0.5 \mathrm{~cm}$ & 28 \\
\hline
\end{tabular}

* Images are not to scale 


\section{Table 4(on next page)}

Seven cephalopod species with GenBank accession number 
1 Table 4: Seven cephalopod species with GenBank accession number

\begin{tabular}{|l|c|c|c|}
\hline Species & $\begin{array}{c}\text { Sample } \\
\text { code }\end{array}$ & $\begin{array}{c}\text { Sequence } \\
\text { ID }\end{array}$ & GenBank Accession number \\
\hline Sepia aculeata & C2-1 & SeqC2-1 & MZ413930 \\
\hline Sepia esculenta & C6-25 & SeqC6-25 & MZ413931 \\
\hline Sepioteuthis lessoniana & C3-1 & SeqC3-1 & MZ413932 \\
\hline Loliolus uyii & S1-1 & SeqS1-1 & MZ413933 \\
\hline Uroteuthis chinensis & S3-1 & SeqS3-1 & MZ413934 \\
\hline Uroteuthis edulis & S4-1 & SeqS4-1 & MZ413935 \\
\hline Amphioctopus aegina & O2-6 & SeqO2-6 & MZ413936 \\
\hline
\end{tabular}

2

3 


\section{Table 5 (on next page)}

Number of traditional features and deep features extracted 
1 Table 5: Number of traditional features and deep features extracted

\begin{tabular}{|l|l|}
\hline Descriptors & Number of features \\
\hline Gray HOG & 108 \\
\hline Colour HOG & 108 \\
\hline MSD & 10 \\
\hline Gray HOG + MSD & 118 \\
\hline Colour HOG + MSD & 118 \\
\hline VGG19 & 4096 \\
\hline ResNet50 & 2048 \\
\hline InceptionV3 & 2048 \\
\hline
\end{tabular}

2 
Table 6(on next page)

Performance for single and hybrid descriptor of traditional features 
1 Table 6 Performance for single and hybrid descriptor of traditional features

\begin{tabular}{|c|c|c|c|c|c|c|c|c|c|c|}
\hline \multirow{3}{*}{ Model } & \multicolumn{10}{|c|}{ Testing Accuracy (\%)* (AUC) } \\
\hline & \multicolumn{2}{|c|}{ Gray HOG } & \multicolumn{2}{|c|}{ Colour HOG } & \multicolumn{2}{|l|}{ MSD } & \multicolumn{2}{|c|}{$\begin{array}{l}\text { Gray HOG + } \\
\text { MSD }\end{array}$} & \multicolumn{2}{|c|}{$\begin{array}{l}\text { Colour HOG + } \\
\text { MSD }\end{array}$} \\
\hline & UB & $\mathbf{L B}$ & UB & $\mathbf{L B}$ & UB & $\mathbf{L B}$ & UB & LB & UB & LB \\
\hline ANN & $\begin{array}{l}54.34 \\
(0.59)\end{array}$ & $\begin{array}{l}52.69 \\
(0.59)\end{array}$ & $\begin{array}{l}60.40 \\
(0.62)\end{array}$ & $\begin{array}{l}68.69 \\
(0.76)\end{array}$ & $\begin{array}{l}55.43 \\
(0.56)\end{array}$ & $\begin{array}{l}44.91 \\
(0.51)\end{array}$ & $\begin{array}{l}61.09 \\
(0.65)\end{array}$ & $\begin{array}{l}58.06 \\
(0.65)\end{array}$ & $\begin{array}{l}64.91 \\
(0.70)\end{array}$ & $\begin{array}{l}73.09 \\
(0.79)\end{array}$ \\
\hline SVM & $\begin{array}{l}46.51 \\
(0.56)\end{array}$ & $\begin{array}{l}45.31 \\
(0.56)\end{array}$ & $\begin{array}{l}51.66 \\
(0.59)\end{array}$ & $\begin{array}{l}66.69 \\
(0.74)\end{array}$ & $\begin{array}{l}62.17 \\
(0.66)\end{array}$ & $\begin{array}{l}52.06 \\
(0.58)\end{array}$ & $\begin{array}{l}52.97 \\
(0.61)\end{array}$ & $\begin{array}{l}51.14 \\
(0.61)\end{array}$ & $\begin{array}{l}59.34 \\
(0.62)\end{array}$ & $\begin{array}{l}68.23 \\
(0.77)\end{array}$ \\
\hline $\mathbf{R F}$ & $\begin{array}{l}57.77 \\
(0.64)\end{array}$ & $\begin{array}{l}51.20 \\
(0.57)\end{array}$ & $\begin{array}{l}66.06 \\
(0.74)\end{array}$ & $\begin{array}{l}71.03 \\
(0.76)\end{array}$ & $\begin{array}{l}64.57 \\
(0.69\end{array}$ & $\begin{array}{l}63.66 \\
(0.68)\end{array}$ & $\begin{array}{l}77.03 \\
(0.84)\end{array}$ & $\begin{array}{l}65.03 \\
(0.72)\end{array}$ & $\begin{array}{l}79.14 \\
(0.87)\end{array}$ & $\begin{array}{l}76.91 \\
(0.81)\end{array}$ \\
\hline KNN & $\begin{array}{l}55.43 \\
(0.61)\end{array}$ & $\begin{array}{l}48.74 \\
(0.55)\end{array}$ & $\begin{array}{l}53.77 \\
(0.62)\end{array}$ & $\begin{array}{l}71.14 \\
(0.75)\end{array}$ & $\begin{array}{l}61.20 \\
(0.66)\end{array}$ & $\begin{array}{l}50.63 \\
(0.58)\end{array}$ & $\begin{array}{l}59.31 \\
(0.67)\end{array}$ & $\begin{array}{l}50.86 \\
(0.58)\end{array}$ & $\begin{array}{l}62.69 \\
(0.69)\end{array}$ & $\begin{array}{l}70.40 \\
(0.74)\end{array}$ \\
\hline DT & $\begin{array}{l}42.40 \\
(0.55)\end{array}$ & $\begin{array}{l}36.86 \\
(0.49)\end{array}$ & $\begin{array}{l}45.77 \\
(0.61)\end{array}$ & $\begin{array}{l}40.29 \\
(0.53)\end{array}$ & $\begin{array}{l}45.71 \\
(0.61)\end{array}$ & $\begin{array}{l}46.46 \\
(0.63)\end{array}$ & $\begin{array}{l}43.31 \\
(0.57)\end{array}$ & $\begin{array}{l}48.69 \\
(0.65)\end{array}$ & $\begin{array}{l}44.97 \\
(0.62)\end{array}$ & $\begin{array}{l}53.14 \\
(0.67)\end{array}$ \\
\hline LR & $\begin{array}{l}50.91 \\
(0.58)\end{array}$ & $\begin{array}{l}50.63 \\
(0.58)\end{array}$ & $\begin{array}{l}55.94 \\
(0.61)\end{array}$ & $\begin{array}{l}65.26 \\
(0.75)\end{array}$ & $\begin{array}{l}42.00 \\
(0.55)\end{array}$ & $\begin{array}{l}41.03 \\
(0.51)\end{array}$ & $\begin{array}{l}60.06 \\
(0.66)\end{array}$ & $\begin{array}{l}56.63 \\
(0.64)\end{array}$ & $\begin{array}{l}62.34 \\
(0.69)\end{array}$ & $\begin{array}{l}69.89 \\
(0.78)\end{array}$ \\
\hline LDA & $\begin{array}{l}57.14 \\
(0.58)\end{array}$ & $\begin{array}{l}45.83 \\
(0.41)\end{array}$ & $\begin{array}{l}64.80 \\
(0.67)\end{array}$ & $\begin{array}{l}61.89 \\
(0.61)\end{array}$ & $\begin{array}{l}62.74 \\
(0.66)\end{array}$ & $\begin{array}{l}59.26 \\
(0.60)\end{array}$ & $\begin{array}{l}74.34 \\
(0.74)\end{array}$ & $\begin{array}{l}58.23 \\
(0.54)\end{array}$ & $\begin{array}{l}76.74 \\
(0.80)\end{array}$ & $\begin{array}{l}64.34 \\
(0.62)\end{array}$ \\
\hline GNB & $\begin{array}{l}41.71 \\
(0.51)\end{array}$ & $\begin{array}{l}44.97 \\
(0.48)\end{array}$ & $\begin{array}{l}48.17 \\
(0.57)\end{array}$ & $\begin{array}{l}53.54 \\
(0.57)\end{array}$ & $\begin{array}{l}64.00 \\
(0.66)\end{array}$ & $\begin{array}{l}52.74 \\
(0.60)\end{array}$ & $\begin{array}{l}51.66 \\
(0.58)\end{array}$ & $\begin{array}{l}50.06 \\
(0.53)\end{array}$ & $\begin{array}{l}54.97 \\
(0.62)\end{array}$ & $\begin{array}{l}57.49 \\
(0.61)\end{array}$ \\
\hline
\end{tabular}


Table 7 (on next page)

Performance of eight classifiers with deep features extracted 
1 Table 7: Performance of eight classifiers with deep features extracted

\begin{tabular}{|l|l|l|l|l|l|l|}
\hline \multirow{2}{*}{ Model } & \multicolumn{5}{l}{ Testing Accuracy* (AUC) } \\
\cline { 2 - 7 } & VGG19 & \multicolumn{2}{l}{ InceptionV3 } & \multicolumn{2}{l|}{ ResNet50 } \\
\cline { 2 - 7 } & UB & LB & UB & LB & UB & LB \\
\hline \multirow{2}{*}{ ANN } & 88.63 & $\mathbf{9 1 . 1 4}$ & 87.54 & 87.49 & $\mathbf{8 6 . 8 6}$ & 85.77 \\
& $(0.95)$ & $\mathbf{( 0 . 9 6 )}$ & $(0.94)$ & $(0.94)$ & $\mathbf{( 0 . 9 3 )}$ & $(0.91)$ \\
\hline \multirow{2}{*}{ SVM } & 81.94 & 88.57 & 81.54 & 84.57 & 79.03 & 83.89 \\
& $(0.11)$ & $(0.94)$ & $(0.89)$ & $(0.91)$ & $(0.90)$ & $(0.92)$ \\
\hline \multirow{2}{*}{ RF } & 85.31 & 89.83 & 84.29 & 82.97 & 85.43 & 83.31 \\
& $(0.93)$ & $(0.95)$ & $(0.90)$ & $(0.90)$ & $(0.93)$ & $(0.90)$ \\
\hline \multirow{2}{*}{ KNN } & 76.97 & 85.60 & 76.00 & 81.09 & 76.74 & 79.31 \\
& $(0.87)$ & $(0.93)$ & $(0.85)$ & $(0.88)$ & $(0.86)$ & $(0.87)$ \\
\hline \multirow{2}{*}{ DT } & 58.63 & 56.63 & 49.37 & 50.63 & 48.11 & 53.20 \\
& $(0.73)$ & $(0.71)$ & $(0.66)$ & $(0.65)$ & $(0.66)$ & $(0.69)$ \\
\hline \multirow{2}{*}{ LR } & 89.66 & 91.71 & 85.77 & 85.37 & 84.86 & 85.83 \\
& $(0.96)$ & $(0.95)$ & $(0.95)$ & $(0.92)$ & $(0.93)$ & $(0.92)$ \\
\hline \multirow{2}{*}{ LDA } & 83.14 & 86.34 & 88.86 & $\mathbf{8 9 . 4 3}$ & 82.11 & 82.34 \\
& $(0.88)$ & $(0.91)$ & $(0.95)$ & $\mathbf{( 0 . 9 5 )}$ & $(0.90)$ & $(0.89)$ \\
\hline \multirow{2}{*}{ GNB } & 82.23 & 86.97 & 77.54 & 77.60 & 67.60 & 70.11 \\
& $(0.85)$ & $(0.89)$ & $(0.82)$ & $(0.83)$ & $(0.72)$ & $(0.75)$ \\
\hline
\end{tabular}

Notes:

* Average testing accuracy from the five-fold $\mathrm{CV}$ results with 10 times runs $\mathrm{UB}=$ Upper beak, $\mathrm{LB}=$ Lower beak AUC $=$ Average area under the precision-recall curve in one of the runs Bolded text indicated the best results for each deep feature model. 
Table 8(on next page)

Comparison of previous and current study 
1 Table 8: Comparison of previous and current study

\begin{tabular}{|c|c|c|c|c|}
\hline \multirow{2}{*}{ Study } & \multirow{2}{*}{ Sample } & \multicolumn{2}{|l|}{ Methodology } & \multirow{2}{*}{ Results } \\
\hline & & $\begin{array}{l}\text { Feature } \\
\text { Extraction }\end{array}$ & Classification & \\
\hline $\begin{array}{l}\text { Orenstein et al. } \\
(2016)\end{array}$ & $\begin{array}{l}\text { Seven } \\
\text { specimens of } \\
\text { Sepia officinalis } \\
\text { (cuttlefish) }\end{array}$ & $\begin{array}{l}\text { Texton-based } \\
\text { (mottle and } \\
\text { pattern) of } \\
\text { cuttlefish }\end{array}$ & SVM & $\begin{array}{l}\text { Best accuracy } \\
=94 \%\end{array}$ \\
\hline $\begin{array}{l}\text { Himabindu et } \\
\text { al. (2017) }\end{array}$ & 50 squid species & $\begin{array}{l}\text { Size } \\
\text { measurements of } \\
\text { mantle, fin and } \\
\text { head }\end{array}$ & ANN & $\begin{array}{l}\text { Best accuracy } \\
=98.6 \%\end{array}$ \\
\hline Jin et al. (2017) & $\begin{array}{l}\text { Three } \\
\text { Loliginidae } \\
\text { Squid Species } \\
\text { (256 samples) }\end{array}$ & $\begin{array}{l}\text { Extract feature } \\
\text { from statolith and } \\
\text { beak }\end{array}$ & $\begin{array}{l}\text { Geometric } \\
\text { outline with } \\
\text { PCA and SDA }\end{array}$ & $\begin{array}{l}\text { Accuracies } \\
\text { between } 75.0 \% \\
-88.7 \%\end{array}$ \\
\hline Current study & $\begin{array}{l}\text { Seven } \\
\text { cephalopod } \\
\text { species (174 } \\
\text { samples) }\end{array}$ & $\begin{array}{l}\text { Traditional } \\
\text { features and deep } \\
\text { features of upper } \\
\text { and lower beaks }\end{array}$ & $\begin{array}{l}\text { ANN, SVM, } \\
\text { RF, KNN, DT, } \\
\text { LR, LDA, } \\
\text { GNB }\end{array}$ & $\begin{array}{l}\text { Best accuracy } \\
=91.14 \%\end{array}$ \\
\hline
\end{tabular}

2 
Figure 1

The framework for cephalopod species identification using integrated analysis of machine learning and deep learning 


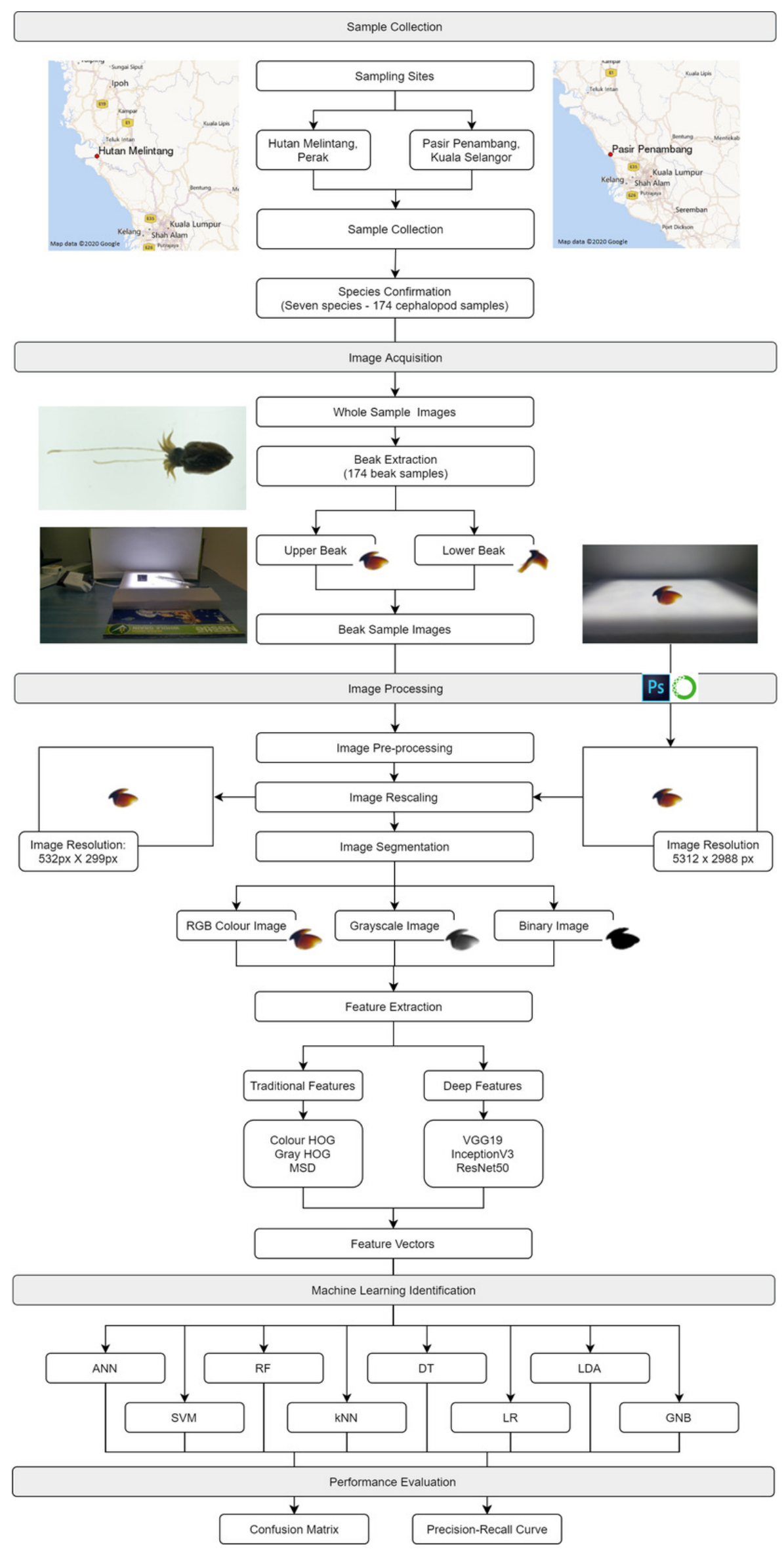




\section{Figure 2}

Set up for the image acquisition for beak samples of the studied cephalopods (a) Lightbox (b) The smartphone was used to capture the photos of the beaks

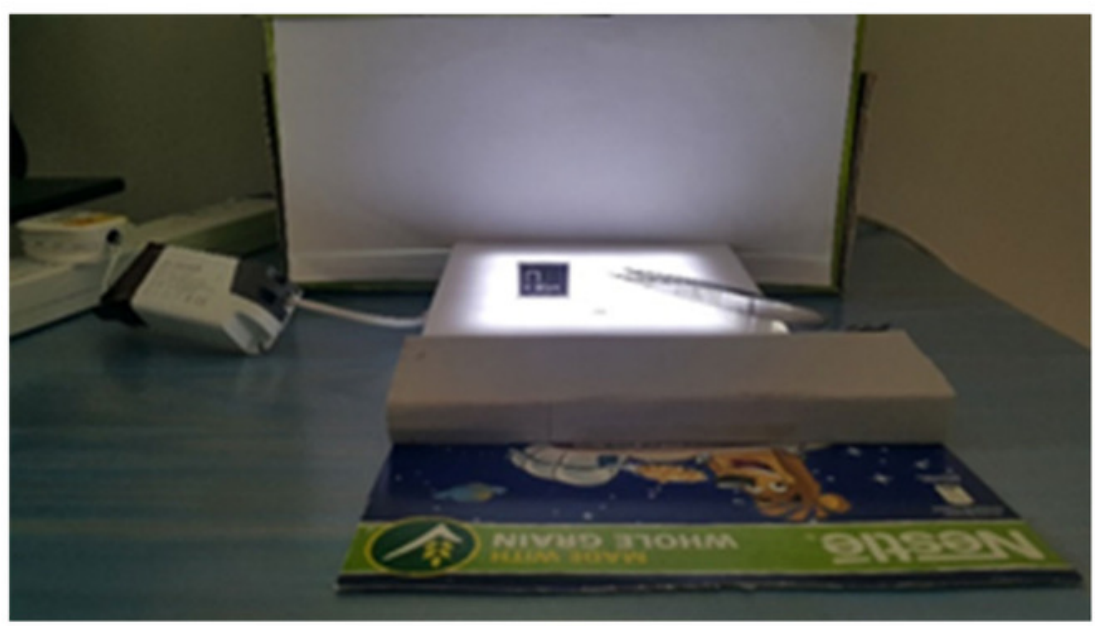

(a)

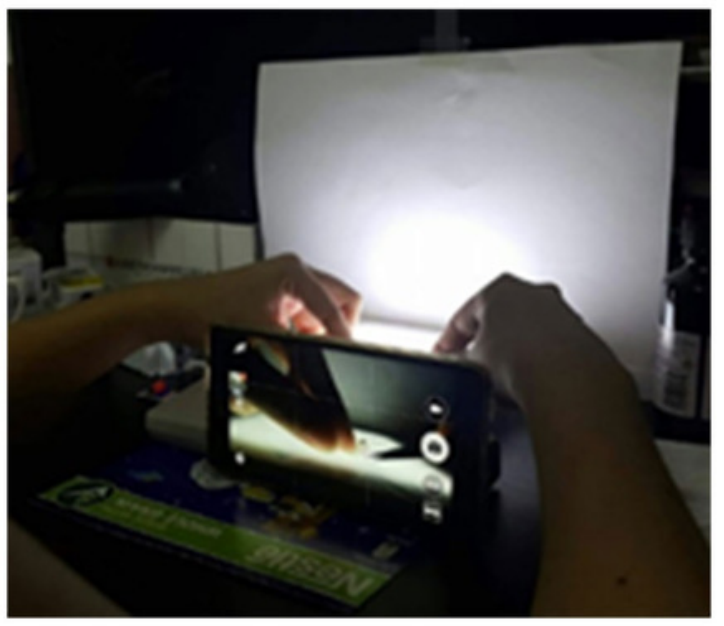

(b) 
Figure 3

Example of Stratified Shuffle Split Cross-Validation Approach for one of the ANN models

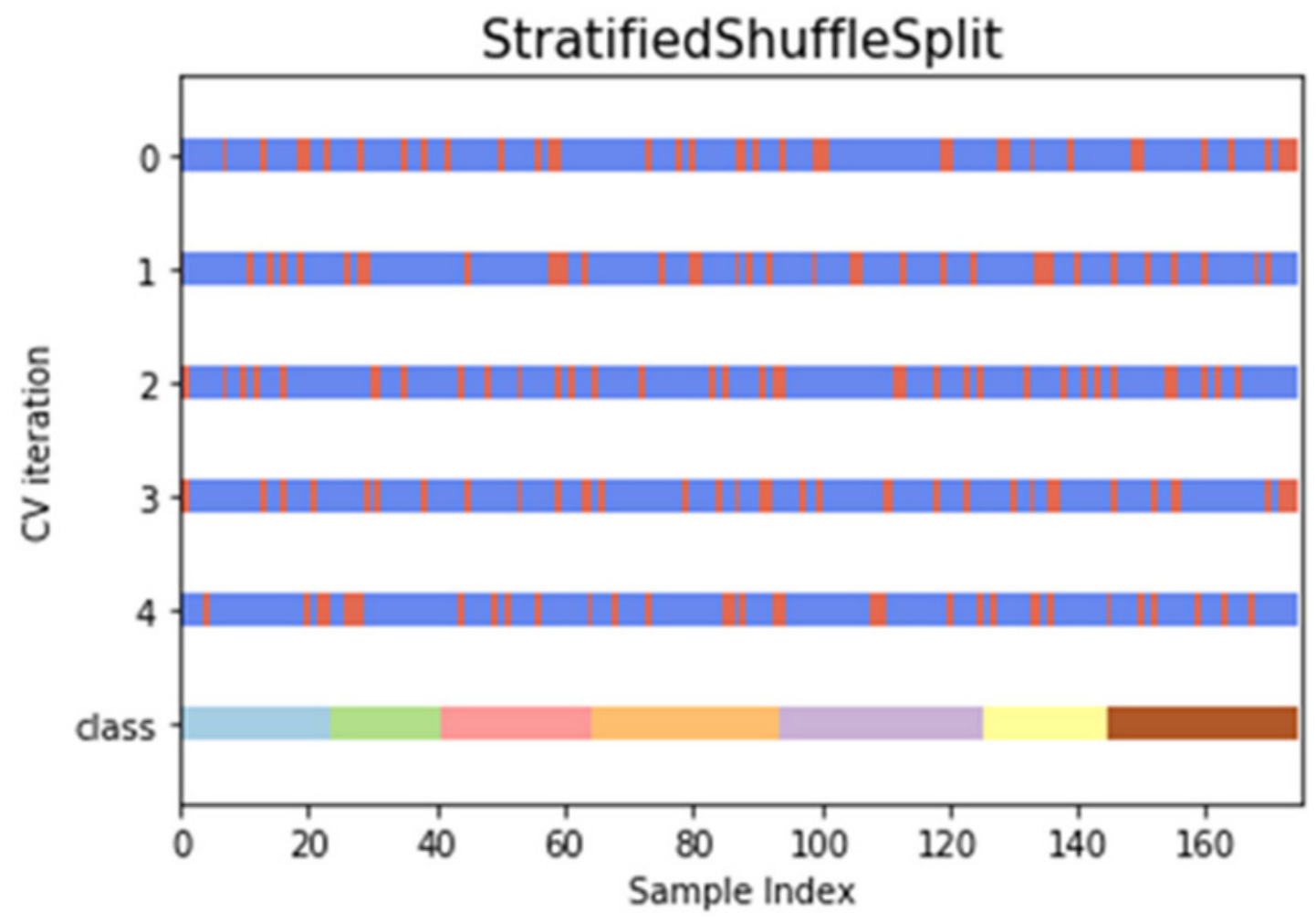

Testing set Training set 


\section{Figure 4}

Performance evaluation from one of the runs in the ANN model with hybrid descriptor (colour HOG +MSD) of lower beak images: (a) Confusion Matrix (b) Precision-Recall Curve.

For the confusion matrix, the precision and recall value of the identification model was computed from the testing set. Each cephalopod species was computed for its precision and recall values to visualize the differences in the performance of the model. The average precision-recall curve of the model was calculated. For the Precision-Recall curve, the area under the curve was measured. The higher the area under the curve, the better the model performance in identifying cephalopod species from the beak images 
(a)

PREDICTED

\begin{tabular}{|c|c|c|c|c|c|c|c|}
\hline & S. aculeata & S. lessoniana & S. esculenta & A. aegina & L. uyz̈ & U.chinensis & U.edulis \\
\hline S. aculeata & 3 & 1 & 1 & 0 & 0 & 0 & 0 \\
\hline S. lessomiana & 0 & 3 & 0 & 0 & 0 & 0 & 0 \\
\hline S. esculenta & 0 & 0 & 5 & 0 & 0 & 0 & 0 \\
\hline A. aegina & 0 & 0 & 0 & 5 & 1 & 0 & 0 \\
\hline L. uÿ̈ & 0 & 0 & 0 & 0 & 6 & 0 & 0 \\
\hline U.chinensis & 0 & 0 & 1 & 0 & 0 & 1 & 2 \\
\hline U.edulis & 0 & 0 & 0 & 0 & 3 & 0 & 3 \\
\hline
\end{tabular}

(b)

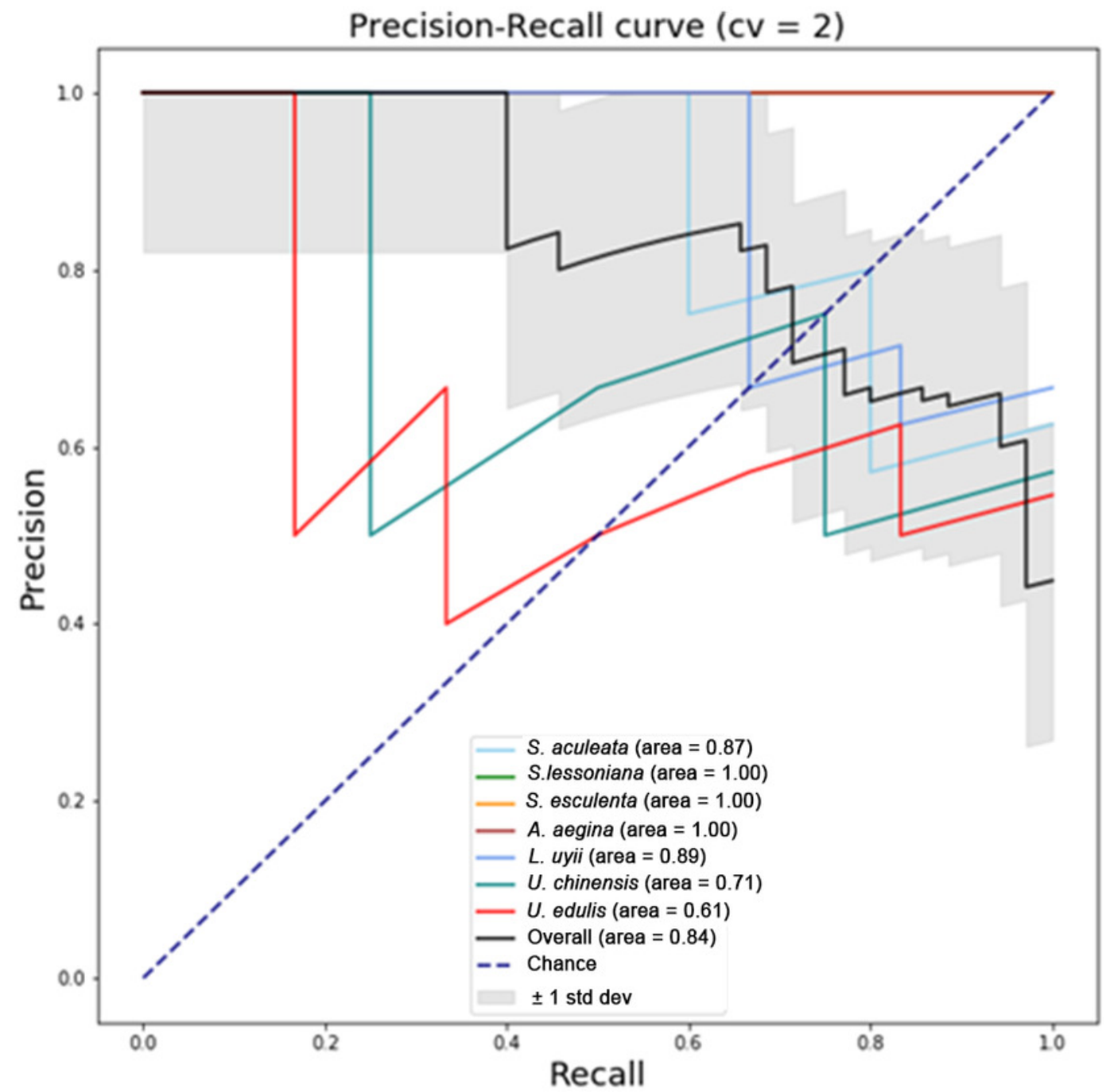




\section{Figure 5}

Performance evaluation from one of the runs in the VGG19-ANN model of lower beak images: (a) Confusion Matrix (b) Precision-Recall Curve

For the confusion matrix, the precision and recall value of the identification model was computed from the testing set. Each cephalopod species was computed for its precision and recall values to visualize the differences in the performance of the model. The average precision-recall curve of the model was calculated.

For the Precision-Recall curve, the area under the curve was measured. The higher the area under the curve, the better the model performance in identifying cephalopod species from the beak images. 
(a)

PREDICTED

\begin{tabular}{|c|c|c|c|c|c|c|c|}
\hline & S. aculeata & S. lessoniana & S. esculenta & A. aegina & L. uyii & U.chinensis & U.edulis \\
\hline S. aculeata & 5 & 0 & 0 & 0 & 0 & 0 & 0 \\
\hline S. lessoniana & 0 & 3 & 0 & 0 & 0 & 0 & 0 \\
\hline S. esculenta & 2 & 0 & 3 & 0 & 0 & 0 & 0 \\
\hline A. aegina & 0 & 0 & 0 & 6 & 0 & 0 & 0 \\
\hline L. uyii & 0 & 0 & 0 & 0 & 5 & 1 & 0 \\
\hline U.chinensis & 0 & 0 & 0 & 0 & 0 & 4 & 0 \\
\hline U.edulis & 0 & 0 & 0 & 0 & 0 & 0 & 6 \\
\hline
\end{tabular}

(b)

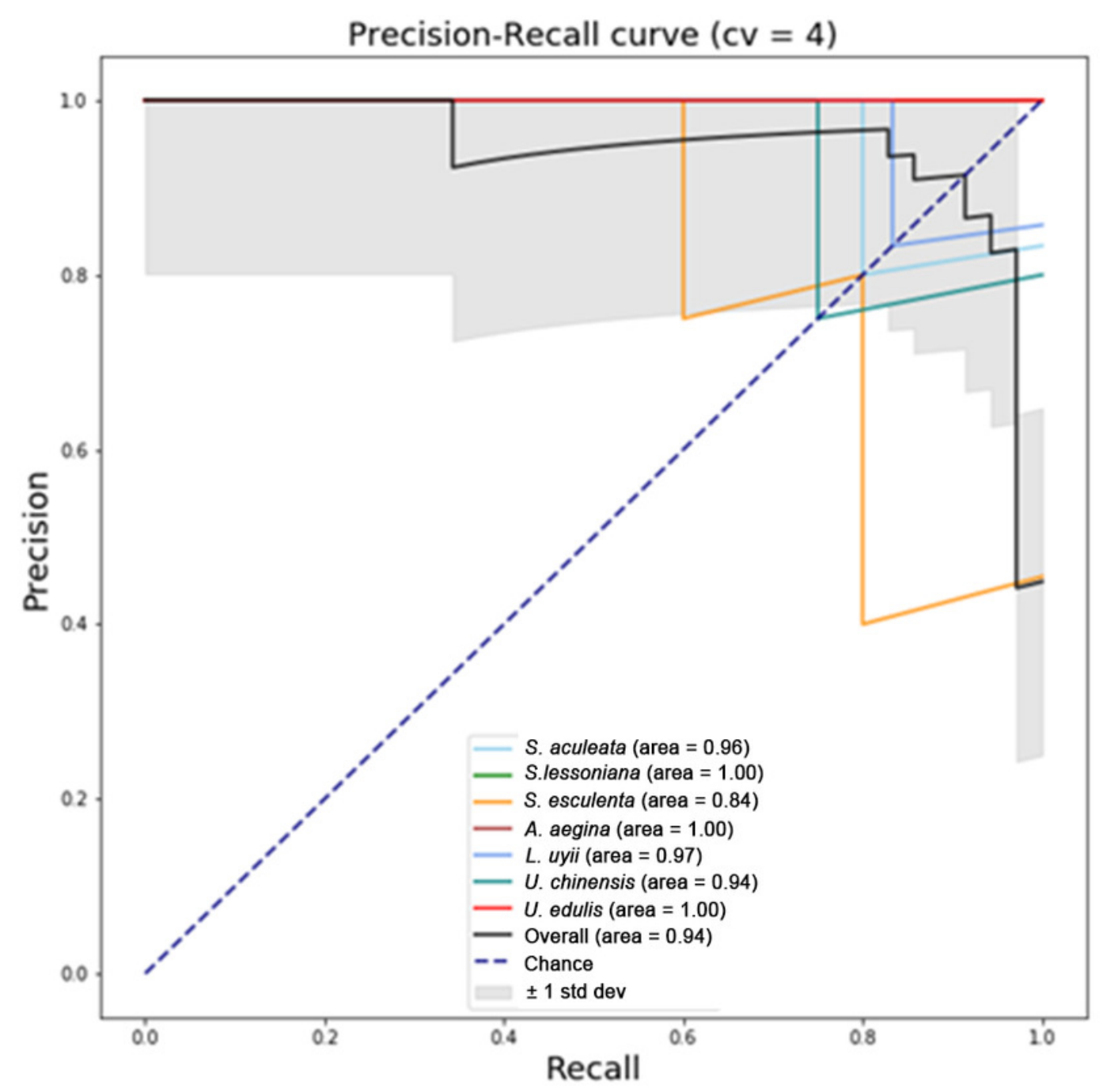

